\title{
Long-Term Clinical Outcome of Early Generation Versus New-Generation Drug-Eluting Stents in 481 Patients Undergoing Rotational Atherectomy: A Retrospective Analysis
}

\author{
Abdelhakim Allali · Erik W. Holy · Dmitry S. Sulimov · Ralph Toelg • \\ Gert Richardt · Mohamed Abdel-Wahab
}

Received: August 7, 2017 / Published online: November 21, 2017

(c) The Author(s) 2017. This article is an open access publication

\section{ABSTRACT}

Introduction: New-generation drug-eluting stents (NG-DES) are superior to early generation DES (EG-DES) in the majority of lesion and patient subsets, but comparative data in patients with severely calcified coronary lesions are lacking. This study aims to compare clinical outcomes of EG-DES and NG-DES in patients undergoing rotational atherectomy (RA) in calcified lesions.

Methods: Data of 268 patients (288 lesions) treated with EG-DES and 213 patients (225 lesions) receiving NG-DES after RA were retrospectively analyzed from a single-center registry. All major adverse cardiac events (MACE) were assessed at 2 years.

Results: Compared to the EG-DES group, patients with NG-DES more commonly had diabetes mellitus $(31.9 \%$ vs. $40.9 \% ; p=0.04)$, left main lesions $(7.6 \%$ vs. $17.3 \% ; p<0.001)$ and chronic total occlusions $(3.5 \%$ vs. $8.5 \%$; $p=0.016)$, and had a higher total stent length (30.5, IQR 20-40 mm, vs. 38, IQR 22-53 mm,

Enhanced content To view enhanced content for this article go to http://www.medengine.com/Redeem/ E3FCF0601AD437DE

A. Allali $(\varangle) \cdot$ E. W. Holy · D. S. Sulimov · R. Toelg . G. Richardt - M. Abdel-Wahab

Heart Center, Segeberger Kliniken GmbH, Academic

Teaching Hospital for the Universities of Kiel,

Lübeck and Hamburg, Bad Segeberg, Germany

e-mail: abdelhakim.allali@segebergerkliniken.de $p<0.001)$. The Kaplan-Meier estimated rate of cardiovascular events at 2 years showed a lower incidence of death $(13.5 \%$ vs. $8.2 \%$, log-rank $p=0.13$; adjusted HR after Cox regression analysis 0.49 ; 95\% CI $0.26-0.92 ; p=0.03$ ) and a lower MACE rate $(31.1 \%$ vs. $21.1 \%$, log-rank $p=0.04$; adjusted HR 0.65 ; 95\% CI 0.42-0.98; $p=0.04)$ in the NG-DES group.

Conclusions: Although RA is performed in more complex patients and lesions in the NG-DES era, use of NG-DES is associated with lower rates of death and MACE at 2 years as compared to EG-DES.

Keywords: Calcified coronary stenosis; Drug-eluting stents; Rotational atherectomy

\section{INTRODUCTION}

Rotational atherectomy (RA) is a safe and effective atheroablative technique for complex heavily calcified coronary lesions $[1,2]$. However, RA as a stand-alone therapy is associated with high rates of restenosis [3, 4], and although results improved with the emergence of bare metal stents (BMS), the elevated rates of target lesion revascularization (TLR) remained an important limitation [5]. With the introduction of drug-eluting stents (DES) and the growing number of coronary interventions in severely calcified morphologies, the interest in RA resurged [6-9]. 
The randomized ROTAXUS (Rotational Atherectomy Prior to Taxus Stent Treatment for Complex Native Coronary Artery Disease) trial showed a superior strategy success of routine lesion preparation using RA compared to balloon angioplasty in the setting of complex calcified coronary lesions treated with early generation paclitaxel-eluting stents, but it failed to demonstrate improved long-term clinical outcomes with such an approach $[10,11]$.

New-generation drug-eluting stents (NG-DES) are characterized by thinner stent strut platforms, polymers with improved biocompatibility and limus-based antiproliferative agents, thereby providing an improved safety and efficacy profile as compared to BMS as well as first-generation drug-eluting devices in the majority of lesion and patient subsets $[12,13]$. Currently, there is a paucity of data supporting the benefit of NG-DES in patients with severely calcified coronary lesions [14]. In particular, it is not known whether delicate NG-DES have enough mechanical stability to make them applicable in this challenging type of lesions. The current study compares clinical outcomes of EG- and NG- DES in an all-comers population of patients with severely calcified lesions treated with RA prior to stent implantation.

\section{METHODS}

This is a retrospective analysis of prospectively collected data in patients who underwent RA followed by DES implantation for the treatment of calcified coronary lesions at a single tertiary center (Heart Center, Segeberger Kliniken, Bad Segeberg, Germany) between November 2002 and June 2015. Patients treated with BMS, with a combination of BMS and DES or early plus new-generation DES as well as bioresorbable vascular scaffolds (BVS) were excluded from this analysis.

For the current study, two groups of patients depending on the type of stent implanted after RA were compared: the first group included patients receiving only EG-DES including the sirolimus-eluting Cypher ${ }^{\mathrm{TM}}$ stent (Cordis, Miami Lakes, FL, USA) and the paclitaxel-eluting Taxus
Liberté $^{\mathrm{TM}}$ stent (Boston Scientific, Boston, MA, USA). The NG-DES group consisted of patients receiving only NG-DES, including the cobaltchromium everolimus-eluting Xience $^{\mathrm{TM}}$ stent (Abbott Vascular, Santa Clara, CA, USA), the platinum-chromium everolimus-eluting Promus ${ }^{\mathrm{TM}}$ stent (Boston Scientific, Natick, MA, USA) as well as the sirolimus-eluting Orsiro $^{\mathrm{TM}}$ stent (Biotronik, Bülach, Switzerland).

Written informed consent was obtained from all patients for analysis of their anonymized data, and data collection was approved by the local ethics committee. All procedures followed were in accordance with the ethical standards of the responsible committee on human experimentation and with the Helsinki Declaration of 1964, as revised in 2013.

In addition to demographic and clinical characteristics of the study population, data collection included angiographic and procedural details as well as early in-hospital outcome and long-term follow-up. Clinical follow-up was obtained either by on-site clinical visit or scripted telephone interview with the patients or their general practitioners.

\section{Procedural Details}

For all cases, RA was performed using the CE-marked Rotablator device (Boston Scientific Scimed Inc., Maple Grove, MN, USA). The burr size was selected aiming at a burr/vessel ratio of 0.5 (max. 0.7 if needed). Rotational speed ranged between 140,000 and 180,000 rotations per minute (rpm). To prevent slow-flow, a continuous intracoronary infusion of unfractioned heparin (UFH), nitroglycerine and verapamil was used during RA. Prior to RA, patients were treated with $325-500 \mathrm{mg}$ aspirin intravenously and an oral loading dose of a P2Y12 inhibitor (Clopidogrel, Prasugrel or Ticagrelor). In addition, patients were administrated a periprocedural anticoagulation with either UFH intra-arterially or bivalirudin. The use of glycoprotein IIb/IIIa inhibitors was at the operator's discretion. Technical details of RA at our institution have been reported in previous publications [8]. 


\section{Definitions, Follow-Up, and Endpoints}

RA was defined as elective in the absence of any previous attempt to cross the lesion with a balloon or a stent. Angiographic success was defined as a final residual stenosis $<30 \%$ and grade 3 thrombolysis in myocardial infarction (TIMI) flow. During hospitalization, occurrence of any adverse event and any additional coronary intervention were registered. Periprocedural myocardial infarction following PCI was defined as CK-MB elevation $>3$ times the upper range limit of normal at $48 \mathrm{~h}$ after the procedure. Major adverse cardiac events (MACE) were defined as all cause death, spontaneous myocardial infarction (MI) and target vessel revascularization (TVR). Death was classified as either cardiac or non-cardiac, and death of unknown cause was adjudicated as cardiac death. Stent thrombosis and myocardial infarction (MI) were defined according to the Academic Research Consortium [15]. TVR was defined as any repeat PCI or surgical bypass of the target vessel. Finally, target lesion revascularization was defined as any repeat revascularization either with PCI or coronary artery bypass graft (CABG) for restenosis or other complication inside the stent implanted during the index procedure or within $5 \mathrm{~mm}$ proximal or distal to the stent.

\section{Statistical Methods}

Continuous variables are expressed as mean \pm standard deviation or median and interquartile range, as appropriate. Categorical variables are expressed as numbers and percentages. Group comparisons were performed using Student's $t$ test or Wilcoxon rank-sum test for continuous variables or Chi-square and Fisher's exact tests for categorical variables. Kaplan-Meier plots of cumulative incidence of MACE, death, MI, TVR, and TLR were constructed from the index procedure until 2-year follow-up, and log-rank tests were used to examine the differences between groups.

Survival times for the two groups were also compared using Cox proportional hazard model. Multivariable method was used to allow for differences in profile between the EG and NG-DES groups. The following covariates were considered: age, gender, diabetes mellitus, hypertension, dyslipidemia, current smoking, family history of coronary artery disease, previous MI, previous PCI, previous CABG, left ventricular ejection fraction, glomerular filtration rate (GFR) $<30 \mathrm{ml} / \mathrm{min}$, lesion type $\mathrm{B} 2 / \mathrm{C}$, chronic total occlusions (CTO), multivessel coronary disease, culprit lesion in the left main (LMT) coronary artery and acute coronary syndrome (ACS). Covariates to be used in multivariable models were found in two stages, first omitting variables with $p$ value $>0.1$ in a model just including the variable and group and then carrying out a backward elimination procedure with the remaining variables. In the backward elimination procedure, non-significant variables were dropped one-by-one until only significant variables remained in the model. All reported $p$ values were two-sided, and $p$ values $<0.05$ were considered statistically significant. Statistical analysis was performed using Stata SE 14 (StataCorp LP, College Station, TX, USA) and SAS version 9.4 (SAS Institute Software $\mathrm{GmbH}$, Vienna, Austria) statistical software.

\section{RESULTS}

During the study period, a total of 588 patients underwent RA. Of these, 107 patients were excluded from the study (52 patients treated with BMS, 14 treated with combination of DES and BMS, 12 treated with a combination of early and new generations DES, five treated with BVS, nine patients treated with experimental stents within clinical trials or in a randomized study where the operator was blinded to the type of stent, and 15 patients with no stent implantation). Thus, 481 patients received only early or only new-generation DES and constitute the population of the current analysis. Of these, 268 $(55.7 \%)$ were treated with EG-DES for 288 lesions (61 lesions with Cypher stent, 225 with Taxus stent and both stent types in two lesions), and 213 patients (44.3\%) received NG-DES for 225 lesions (82 lesions with Xience stent, 59 with Promus stent, 72 with Orsiro and 12 lesions were treated with a mixture of two NG-DES). 


\section{Patient, Angiographic, and Procedural Characteristics}

Baseline clinical characteristics are reported in Table 1 . The mean age of the study population was $72 \pm 8$ years and 353 patients $(73.3 \%)$ were males. Left ventricular ejection fraction (LV-EF) was reduced in $29.2 \%$ of the patients. $24.7 \%$ of RA was performed in patients presenting with an acute coronary syndrome. EG-DES and NG-DES patients were not significantly different in the latter aspects. However, significantly more patients in the EG-DES group had dyslipidemia $(75.6 \%$ vs. $61.1 \% ; p=0.001)$, a family history of premature coronary artery disease ( $26.3 \%$ vs. $16.8 \% ; p=0.014)$ or MI $(25.7 \%$ vs. $16.4 \% ; p=0.014)$, while in the NG-DES group diabetes mellitus $(31.9 \%$ vs. $40.9 \% ; p=0.04)$ and multivessel coronary artery disease $(82.5 \%$ vs. $90.9 \% ; p=0.008$ ) were more frequent.

Lesion characteristics and procedural details are presented in Table 2 . In general, the NG-DES cohort had more complex lesions and more complex procedures. In the NG-DES group 39 lesions were located in LMT whereas only 22 lesions involving the LMT were treated in the EG-DES group $(p<0.001)$. Furthermore, the number of CTO in the NG-DES group was significantly higher (3.5 vs. $8.5 \% ; p=0.016)$. Patients who received NG-DES after RA had a significantly higher rate of multiple stent implantation ( 48.6 vs. $63.1 \% ; p=0.001)$ as well as a longer median stent length (30.5, IQR 20-40 mm vs. 38 , IQR $22-53 \mathrm{~mm} ; p<0.001$ ). High angiographic success rates were achieved in both groups (97.2 vs. $96.9 \% ; p=0.82)$. Iatrogenic coronary perforation occurred in only one case in the EG-DES but was reported in seven patients in the NG-DES group $(p=0.012)$. Other procedural complications were rare and similar between the groups.

\section{In-Hospital Outcome}

In-hospital death occurred in 1.1 and $1.4 \%$ of the patients in the EG-DES and NG-DES group, respectively $(p=0.77)$. All deaths were due to cardiovascular cause. Thirty-two patients developed MI during hospitalization (6.6\%), of which three were Q-wave MI. Overall, the incidence of peri-procedural MI was higher in the group of patients who received NG-DES after RA $(8.9 \%)$ compared to the patients who were treated with EG-DES (4.8\%) even though statistical significance was not reached $(p=0.07)$. In-hospital TVR $(0.8 \%$ vs. $0.5 \%, p=0.57)$ and TLR $(0.4 \%$ vs. $0.5 \%, p=0.69)$ were not significantly different between EG-DES and NG-DES groups.

\section{Two-Year Outcome}

Long-term clinical follow-up was available in 457 patients with a median follow-up period of 32 months (IQR 23-60) in the EG-DES group and 17 months in the NG-DES population (IQR 12-31) (Fig. 1). There was no significant difference between the groups for the estimated rate of MI $(4.9 \%$ vs. $4.1 \%, \log \operatorname{rank} p=0.89)$ and TVR (17.6\% vs. $12.9 \%$, log-rank $p=0.19)$ at 2 years, with a trend towards a lower rate of TLR $(12.7 \%$ vs. $7.9 \%, \log$-rank $p=0.13)$ in the NG-DES group. All-cause mortality was numerically higher in the EG-DES group $(13.5 \%$ vs. $8.2 \%, \log$-rank $p=0.13)$ due to a significantly higher incidence of death from non-cardiovascular causes $(8.2 \%$ vs. $1.5 \%, \log$ rank $p=0.05)$. Cardiovascular mortality was not significantly different $(5.8 \%$ vs. $6.8 \%$, $\log$-rank $p=0.64$ ). However, the Kaplan-Meier estimated rate of MACE showed a significant reduction in the EG-DES group $(31.1 \%$ vs. $21.1 \%$, log-rank $p=0.04$ ) (Fig. 1). By multivariable analysis, the use of new-generation DES was independently associated with a lower incidence of all cause mortality (HR $0.49 ; 95 \%$ CI $0.26-0.92 ; p=0.03$ ), and the superiority of NG-DES for reducing MACE rate was confirmed (HR 0.65; 95\% CI 0.42-0.98; $p=0.04$ ) (Fig. 2). Cardiovascular mortality was not statistically different between the two groups (HR 0.82; $95 \%$ CI $0.37-1.85$ ) as well as the incidence of definite and probable stent thrombosis $(0.9 \%$ in the EG-DES and $2.4 \%$ in NG-DES group, log-rank $p=0.13$, adjusted HR 3.33; 95\% CI $0.64-17.28 ; p=0.15)$. 
Table 1 Baseline clinical characteristics of the study population (481 patients)

\begin{tabular}{|c|c|c|c|c|}
\hline & $\begin{array}{l}\text { Overall }(n=481 \\
\text { patients })\end{array}$ & $\begin{array}{l}\text { EG-DES ( } n=268 \\
\text { patients) }\end{array}$ & $\begin{array}{l}\text { NG-DES }(n=213 \\
\text { patients) }\end{array}$ & $p$ value* \\
\hline Age (years) & $72 \pm 8$ & $71 \pm 8$ & $72 \pm 9$ & 0.14 \\
\hline Male sex & $353(73.4 \%)$ & $195(72.8 \%)$ & $158(74.2 \%)$ & 0.73 \\
\hline \multicolumn{5}{|l|}{ Cardiovascular risk factors } \\
\hline Diabetes mellitus & $170(35.9 \%)$ & $85(31.9 \%)$ & $85(40.9 \%)$ & 0.04 \\
\hline Hypertension & $434(91.6 \%)$ & $239(89.9 \%)$ & $195(93.7 \%)$ & 0.13 \\
\hline Dyslipidemia & $328(69.2 \%)$ & $201(75.6 \%)$ & $127(61.1 \%)$ & 0.001 \\
\hline Current smoking & $166(35 \%)$ & $96(36.1 \%)$ & $70(33.7 \%)$ & 0.58 \\
\hline $\begin{array}{l}\text { Family history of premature } \\
\text { CAD }\end{array}$ & $105(22.2 \%)$ & $70(26.3 \%)$ & $35(16.8 \%)$ & 0.01 \\
\hline Height $(\mathrm{cm})$ & $172 \pm 9$ & $172 \pm 9$ & $171 \pm 9$ & 0.48 \\
\hline Weight $(\mathrm{kg})$ & $82 \pm 16$ & $83 \pm 16$ & $81 \pm 17$ & 0.65 \\
\hline Body mass index $\left(\mathrm{kg} / \mathrm{m}^{2}\right)$ & $27.8 \pm 4.8$ & $27.8 \pm 4.8$ & $27.8 \pm 4.9$ & 0.83 \\
\hline LV ejection fraction & $52 \pm 14$ & $53 \pm 11$ & $51 \pm 14$ & 0.19 \\
\hline LV ejection fraction $<50 \%$ & $138(29.2 \%)$ & $71(27 \%)$ & $67(32.1 \%)$ & 0.23 \\
\hline \multicolumn{5}{|l|}{ Clinical history } \\
\hline Multivessel disease & $412(86.2 \%)$ & $221(82.5 \%)$ & $191(90.9 \%)$ & 0.008 \\
\hline Prior myocardial infarction & $104(21.6 \%)$ & $69(25.7 \%)$ & $35(16.4 \%)$ & 0.01 \\
\hline Prior PCI & $183(38 \%)$ & $92(34.3 \%)$ & $91(42.33 \%)$ & 0.06 \\
\hline Prior $\mathrm{CABG}$ & $86(17.9 \%)$ & $42(15.7 \%)$ & $44(20.7)$ & 0.16 \\
\hline Renal dialysis & $9(1.9 \%)$ & $2(0.75 \%)$ & $7(3.3 \%)$ & 0.08 \\
\hline Severe CKD $($ GFR < 30) & $34(7.7 \%)$ & $17(6.5 \%)$ & $17(8 \%)$ & 0.49 \\
\hline Clinical presentation & & & & 0.22 \\
\hline Stable CAD & $362(75.3 \%)$ & $196(73.1)$ & $166(77.9 \%)$ & \\
\hline ACS & $119(24.7 \%)$ & $72(26.9 \%)$ & $47(22.1 \%)$ & \\
\hline
\end{tabular}

Data presented as mean \pm standard deviation or number and percentage

$A C S$ acute coronary syndrome, $C A B G$ coronary artery bypass grafting, $C K D$ chronic kidney disease, $E G$-DES early generation drug-eluting stents, $C A D$ coronary artery disease, GFR glomerular filtration rate, $L V$ left ventricular, $N G-D E S$ new-generation drug-eluting stents, $P C I$ percutaneous coronary intervention, $R A$ rotational atherectomy ${ }^{*} p$ value for comparison EG-DES vs. NG-DES

\section{DISCUSSION}

The presence of calcified coronary arteries is associated with worse outcomes in the general population and in patients undergoing revascularization $[16,17]$. In the field of surgical revascularization, severely calcified lesions have been associated with atheroembolic complications and incomplete revascularization after coronary artery bypass graft surgery (CABG). In 
Table 2 Angiographic and procedural characteristics (513 lesions)

\begin{tabular}{|c|c|c|c|c|}
\hline & $\begin{array}{l}\text { Overall ( } n=513 \\
\text { lesions) }\end{array}$ & $\begin{array}{l}\text { EG-DES ( } n=288 \\
\text { lesions) }\end{array}$ & $\begin{array}{l}\text { NG-DES }(n=225 \\
\text { lesions) }\end{array}$ & $p$ value $^{*}$ \\
\hline Target vessel & & & & $<0.001$ \\
\hline Left main & $61(11.9 \%)$ & $22(7.6 \%)$ & $39(17.3)$ & \\
\hline Left anterior descending & $259(50.5 \%)$ & $171(59.4 \%)$ & $88(39.1 \%)$ & \\
\hline Right coronary artery & $66(12.9 \%)$ & $36(12.5 \%)$ & $30(13.3 \%)$ & \\
\hline Left circumflex & $127(24.8 \%)$ & $59(20.5 \%)$ & $68(30.2)$ & \\
\hline Chronic total occlusion & $29(5.6 \%)$ & $10(3.5 \%)$ & $19(8.5 \%)$ & 0.01 \\
\hline Bifurcation lesion & $201(39.2 \%)$ & $109(37.8 \%)$ & $92(40.9 \%)$ & 0.48 \\
\hline Ostial lesion & $117(22.8 \%)$ & $61(21.2 \%)$ & $56(24.9 \%)$ & 0.32 \\
\hline ACC/AHA type B2/C & $437(85.2 \%)$ & $226(78.5 \%)$ & $211(93.8 \%)$ & $<0.001$ \\
\hline Elective RA & $312(60.8 \%)$ & $207(71.9 \%)$ & $105(46.7 \%)$ & $<0.001$ \\
\hline Predilatation & $456(88.9 \%)$ & $250(86.8 \%)$ & $206(91.6 \%)$ & 0.07 \\
\hline Burr sizes & & & & 0.07 \\
\hline 1.25 & $135(26.3 \%)$ & $63(21.9 \%)$ & $72(32 \%)$ & \\
\hline 1.5 & $234(45.6 \%)$ & $138(47.9 \%)$ & $96(42.7 \%)$ & \\
\hline 1.75 & $111(21.6 \%)$ & $66(22.9 \%)$ & $45(20 \%)$ & \\
\hline 2 & $33(6.4 \%)$ & $21(7.3 \%)$ & $12(5.3 \%)$ & \\
\hline More than 1 burr & $76(14.8 \%)$ & $42(14.6 \%)$ & $35(15.1 \%)$ & 0.21 \\
\hline Multiple stenting & $282(55 \%)$ & $140(48.6 \%)$ & $142(63.1 \%)$ & 0.001 \\
\hline Number of implanted stents & $1.8 \pm 0.9$ & $1.7 \pm 0.8$ & $2 \pm 0.9$ & $<0.001$ \\
\hline Stent diameter & $2.93 \pm 0.42$ & $2.93 \pm 0.37$ & $2.93 \pm 0.48$ & 0.84 \\
\hline Total stent length per lesion & $32(22-48)$ & $30.5(20-40)$ & $38(22-53)$ & $<0.001$ \\
\hline Burr/artery ratio & $0.52 \pm 0.08$ & $0.53 \pm 0.08$ & $0.52 \pm 0.09$ & 0.12 \\
\hline Postdilatation & $312(61.2 \%)$ & $163(57.2 \%)$ & $149(66.2 \%)$ & 0.04 \\
\hline $\begin{array}{l}\text { Postdilatation balloon size } \\
\qquad(\mathrm{mm})\end{array}$ & $3.34 \pm 0.52$ & $3.29 \pm 0.47$ & $3.40 \pm 0.58$ & 0.06 \\
\hline Slow flow & $15(2.9 \%)$ & $5(1.7 \%)$ & $10(4.4 \%)$ & 0.07 \\
\hline Dissection & $35(6.8 \%)$ & $15(5.2 \%)$ & $20(8.9 \%)$ & 0.10 \\
\hline Perforation & $9(1.75 \%)$ & $1(0.3 \%)$ & $8(3.6 \%)$ & 0.01 \\
\hline Pericardial effusion & $11(2.1 \%)$ & $4(1.4 \%)$ & $7(3.1 \%)$ & 0.22 \\
\hline Procedural duration (min) & $85 \pm 43$ & $78 \pm 44$ & $95 \pm 41$ & $<0.001$ \\
\hline Fluoroscopy time (min) & $22(15-33)$ & $21(14-31)$ & $25(16-36)$ & 0.003 \\
\hline Contrast amount (ml) & $226 \pm 116$ & $219 \pm 114$ & $234 \pm 119$ & 0.15 \\
\hline
\end{tabular}


Table 2 continued

\begin{tabular}{lllll}
\hline & $\begin{array}{l}\text { Overall }(n=513 \\
\text { lesions })\end{array}$ & $\begin{array}{l}\text { EG-DES }(n=288 \\
\text { lesions })\end{array}$ & $\begin{array}{l}\text { NG-DES }(n=225 \\
\text { lesions })\end{array}$ & $p$ value* \\
\hline Angiographic success & $498(97.1 \%)$ & $280(97.2 \%)$ & $218(96.9 \%)$ & 0.82 \\
\hline
\end{tabular}

Data presented as mean \pm standard deviation, median and interquartile range or number and percentage $A C C / A H A$ American College of Cardiology, American Heart Association, EG-DES early generation drug-eluting stents, $N G$-DES new generation drug-eluting stents, $R A$ rotational atherectomy

${ }^{*} p$ value for comparison EG-DES vs. NG-DES

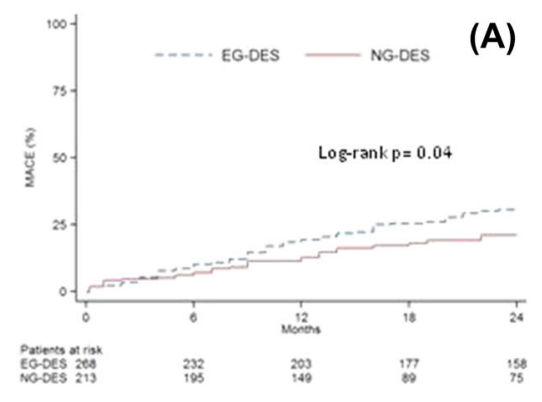

(A)
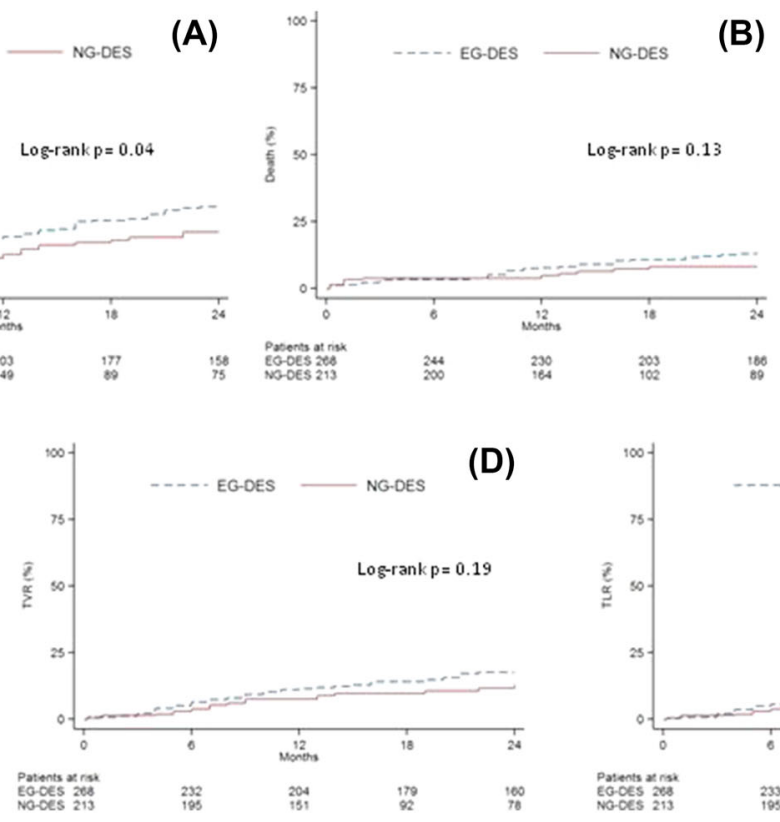

Fig. 1 Kaplan-Meier curve for the cumulative incidence of MACE (a), death (b), MI (c), TVR (d), and TLR (e) in patients treated with EG-DES vs. NG-DES after rotational atherectomy. EG-DES early generation drug-eluting stents,

percutaneous coronary treatment, calcified lesions increase the likelihood of procedural failure and complications after balloon angioplasty [18]. Lesion preparation by improving vessel compliance with cutting and scoring balloon has been demonstrated to enhance DES expansion [19]. Rotational atherctomy exerts a differential ablative effect on hard and soft surfaces, transforming the calcified superficial part of the plaque into small particles. Rotational atherectomy became the most popular atheroablative method in contemporary percutaneous coronary revascularization since the introduction of drug-eluting-stents, which have considerably reduced the rate of restenosis [1].

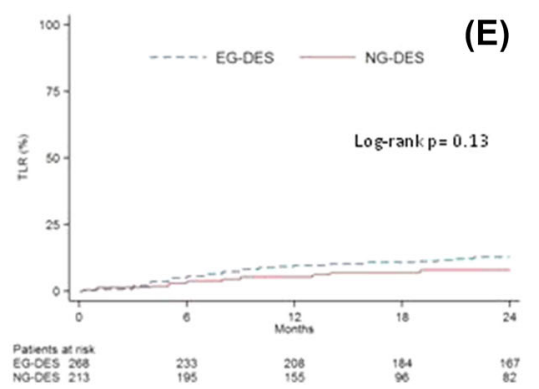

$N G$-DES new-generation drug-eluting stents, $M A C E$ major adverse cardiac events, $M I$ myocardial infarction, $T L R$ target lesion revascularization, TVR target vessel revascularization

In this retrospective analysis, we analyzed the performance of NG-DES compared to EG-DES after RA. The main finding of this study is that NG-DES resulted in lower rates of mortality and major adverse cardiac events at 2 years in an all-comers population of patients treated with RA, despite the fact that they were used in more complex patients and lesions.

Naturally, most patients receiving EG-DES were included in the early period of the registry, while patients with NG-DES were treated more recently. The different time periods might point towards changing indications for RA and explains at least in part the difference observed in lesion characteristics between the groups. 


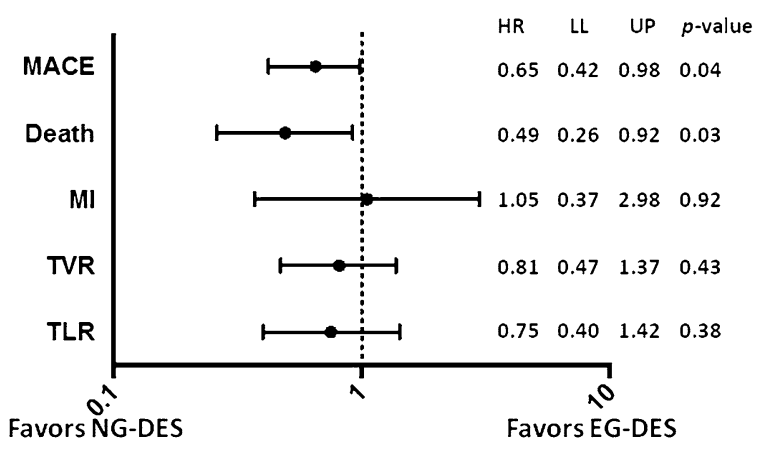

Fig. 2 Adjusted interaction between the type of implanted stent and outcomes at 2 years. Variables are adjusted using multivariable Cox regression analysis and reported as hazard ratio with $95 \%$ confidence interval. $E G-D E S$ early generation drug-eluting stents, $H R$ hazard ratio, $N G$-DES new-generation drug-eluting stents, $L L$ lower limit, $M A C E$ major adverse cardiac events, $M I$ myocardial infarction, $T L R$ target lesion revascularization, TVR target vessel revascularization, $U L$ upper limit

After the ROTAXUS study [10] and the publication of the ESC/EACTS guidelines on myocardial revascularization [20] we confined the use of RA to bailout situations or very complex lesions, which is mirrored in the NG-DES group. Consequently, longer stents and procedures as well as more peri-procedural complications such as no reflow and coronary perforations were observed in the NG-DES group. Nevertheless, the technical aspects of RA such as burr size, burr to artery ratio and the use of multiple burrs were constant throughout the study periods and the selection bias did not result in lower angiographic success rates or significantly worse in-hospital outcomes.

Calcified coronary lesions are more likely to have suboptimal results after PCI due to their resistant burden which may lead to incomplete stent expansion, damage to the polymer/drug coating during stent advancement and impairment of local drug delivery through the calcium [21]. Previous studies reported poor outcomes after PCI of calcified lesions. Généreux et al. in a pooled analysis form the HORIZONS-AMI (Harmonizing Outcomes with Revascularization and Stents in Acute Myocardial Infarction) and ACUITY (Acute Catheterization and Urgent Intervention Triage Strategy) trials reported a MACE rate of $16.1 \%$ at 1 year in patients with moderate/severe coronary calcified lesions and demonstrated that lesion calcification was strongly predictive of stent thrombosis and ischemic TLR [22]. In the ROTAXUS randomized trial, the systematic use of RA before paclitaxel-eluting TAXUS stent implantation did not result in an improvement of 9-months and 2-year clinical outcomes with MACE rates up to $29.4 \%$ after 2 years $[10,11]$. RA-related thermal injury and platelet activation may result in greater neointimal hyperplasia and higher late lumen loss after PCI, which counterbalances the higher acute luminal gain obtained during the index procedure $[10,21]$. In our analysis, $78 \%$ of patients in the EG-DES group received the TAXUS stent and MACE rate at 2 years was similar to the rate reported in the ROTAXUS study.

It should be underlined that the superiority of NG-DES in terms of reducing MACE in the present study was mainly driven by a reduction in the rate of mortality, while the reduction in the TVR rate was less pronounced. As the technique of RA and the adjunctive therapies did not change between either of the study groups, an inherent mortality advantage might come with the implantation of NG-DES. Accordingly, by statistical risk adjustment models, the use of new-generation DES was independently associated with significant lower mortality.

Similar results were reported from the SCAAR registry, where the mortality reduction by NG-DES was at least as strong as the antirestenotic effects compared to BMS as well as EG-DES [23]. Potential mechanisms of NG-DES superiority come from histo-pathological studies in autopsy cases. NG-DES demonstrate greater endothelial strut coverage with less inflammation, less fibrin deposition, and less late and very late stent thrombosis compared to EG-DES [24].

Differences in mortality in PCI trials comparing both device generations are usually demonstrated after long follow-up periods. In the SPIRIT (Clinical Evaluation of the Xience V Everolimus Eluting Coronary Stent System in the Treatment of Patients with De Novo Coronary Artery Lesions) trials the clinical superiority of everolimus-eluting stents over paclitaxel-eluting stents with respect to allcause mortality was not documented before the 
final 3-year clinical results [25]. In the present study, the long duration of follow-up probably made the survival benefit with NG-DES apparent. Nonetheless, even after 2-year follow-up, everolimus eluting stents were not superior to paclitaxel eluting stents in diabetics as shown in a meta-analysis of the SPIRIT and COMPARE trials, which is remarkable since $40 \%$ of our NG-DES patients suffered from diabetes [26].

In the RA field, Iannaccone et al. recently performed a retrospective analysis of outcome of RA in very long coronary lesions from the ROTATE registry. In this study a multivariate analysis as well as a sensitivity analysis showed that the use of NG-DES was protective against MACE [27].

\section{Study Limitations}

Some limitations of the current study need to be mentioned. First, the analysis was conducted in a single-center, retrospective and non-randomized study and therefore has all the limitations of an observational study. Second, both study groups were not uniform in the components of the stents, but represent common patterns of both DES generations. Third, the groups were treated at different time periods and thus operator experience might have influenced the results. Fourth, many differences were observed between the groups in their clinical and angiographic baseline characteristics. Furthermore, some important parameters that could influence outcome such as the use of intravascular imaging and duration of dual anti-platelet therapy were not collected and analyzed in the registry. Additionally, the clinical implication of this study is limited with the fact that currently almost all patients are treated with NG-DES. Finally, the difference observed in all cause morality could be the result of a degree of unmeasured confounding in this study. Although meticulous statistical methods have been used to adjust for baseline differences, unmeasured confounders can never be excluded. Nevertheless, the analyzed data is from one of the largest cohort of patients treated with RA and a high rate of long-term clinical follow-up was achieved.

\section{CONCLUSIONS}

Despite the treatment of more complex lesions with new-generation as compared to early generation DES, use of NG-DES was associated with lower rates of death and major adverse cardiac events at 2 years in a population of patients with severely calcified coronary lesions treated with RA.

\section{ACKNOWLEDGEMENTS}

Funding. No funding or sponsorship was received for this study of publication of this article. Article processing charges were funded by the authors.

Authorship. All named authors meet International Committee of Medical Journal Editors (ICMJE) criteria for authorship for this manuscript, take responsibility for the integrity of the work as a whole, and have given final approval to the revision to be published.

Thanking Participants. We thank Dr. Derek R. Robinson (Senior Lecturer of Statistics, University of Sussex, Brighton, England) for his professional statistical support. We are grateful for the clinical research group at the Herzzentrum Segeberger Kliniken GmbH, especially Mrs. Monika Bahsen-Maass, Mrs. Frederike Geyer and Daniela Schürmann-Kuchenbrandt for their assistance.

Disclosures. Mohamed Abdel-Wahab reports receiving institutional research grants from St. Jude Medical and Biotronik and lecture fees from Edwards Lifesciences and Boston Scientific, and is a proctor for Boston Scientific. Gert Richardt reports receiving institutional research grants from St. Jude Medical and Biotronik and lecture fees from Edwards Lifesciences and Boston Scientific. Erik W. Holy is currently supported by an EAPCI training grant sponsored by Edwards Lifesciences. Ralph Toelg reports receiving personal fees from Biotronik and Abbott Vascular. Abdelhakim Allali and Dmitry S. Sulimov have nothing to disclose. 
Compliance with Ethics Guidelines. All procedures followed were in accordance with the ethical standards of the responsible committee on human experimentation and with the Helsinki Declaration of 1964, as revised in 2013. Informed consent was obtained from all patients for being included in the study.

Data Availability. The datasets generated during and/or analyzed during the current study are available from the corresponding author on reasonable request.

Open Access. This article is distributed under the terms of the Creative Commons Attribution-NonCommercial 4.0 International License (http://creativecommons.org/licenses/ by-nc/4.0/), which permits any noncommercial use, distribution, and reproduction in any medium, provided you give appropriate credit to the original author(s) and the source, provide a link to the Creative Commons license, and indicate if changes were made.

\section{REFERENCES}

1. Barbato E, Carrié D, Dardas P, Fajadet J, Gaul G, Haude M, Khashaba A, Koch K, Meyer-Gessner M, Palazuelos J, Reczuch K, Ribichini FL, Sharma S, Sipötz J, Sjögren I, Suetsch G, Szabó G, Valdés-Chávarri $M$, Vaquerizo $B$, Wijns $W$, Windecker S, de Belder A, Valgimigli M, Byrne RA, Colombo A, Di Mario C, Latib A, Hamm C. European expert consensus on rotational atherectomy. EuroIntervention. $2015 ; 11(1): 30-6$.

2. Tomey MI, Kini AS, Sharma SK. Current status of rotational atherectomy. JACC Cardiovasc Interv. $2014 ; 7(4): 345-53$.

3. Reifart N, Vandormael M, Krajcar M, Göhring S, Preusler W, Schwarz F, Störger H, Hofmann M, Klöpper J, Müller S, Haase J. Randomized comparison of angioplasty of complex coronary lesions at a single center. Excimer Laser, Rotational Atherectomy, and Balloon Angioplasty Comparison (ERBAC) Study. Circulation. 1997;96(1):91-8.

4. Mauri L, Reisman M, Buchbinder M, Popma JJ, Sharma SK, Cutlip DE, Ho KK, Prpic R, Zimetbaum PJ, Kuntz RE. Comparison of rotational atherectomy with conventional balloon angioplasty in the prevention of restenosis of small coronary arteries: results of the Dilatation vs Ablation Revascularization Trial Targeting Restenosis (DART). Am Heart J. 2003;145(5):847-54.

5. Moussa I, Di Mario C, Moses J, Reimers B, Di Francesco L, Martini G, Tobis J, Colombo A. Coronary stenting after rotational atherectomy in calcified and complex lesions. Angiographic and clinical follow-up results. Circulation. 1997;96(1):128-36.

6. Khattab AA, Otto A, Hochadel M, Toelg R, Geist V, Richardt G. Drug-eluting stents versus bare metal stents following rotational atherectomy for heavily calcified coronary lesions: late angiographic and clinical follow-up results. J Interv Cardiol. 2007;20(2):100-6.

7. de Lara Lara J, Pinar E, Ramón Gimeno J, Hurtado JAA, Lacunza J, Valdesuso R, Valdés Chávarri M. Percutaneous coronary intervention in heavily calcified lesions using rotational atherectomy and paclitaxel-eluting stents: outcomes at one year. Rev Esp Cardiol. 2010;63(1):107-10.

8. Abdel-Wahab M, Baev R, Dieker P, Kassner G, Khattab AA, Toelg R, Sulimov D, Geist V, Richardt G. Long-term clinical outcome of rotational atherectomy followed by drug-eluting stent implantation in complex calcified coronary lesions. Catheter Cardiovasc Interv. 2013;81(2): 285-91.

9. Furuichi S, Sangiorgi GM, Godino C, Airoldi F, Montorfano M, Chieffo A, Michev I, Carlino M, Colombo A. Rotational atherectomy followed by drug-eluting stent implantation in calcified coronary lesions. EuroIntervention. 2009;5(3):370-4.

10. Abdel-Wahab M, Richardt G, Joachim Büttner $H$, Toelg R, Geist V, Meinertz T, Schofer J, King L, Neumann F-JJ, Khattab AA. High-speed rotational atherectomy before paclitaxel-eluting stent implantation in complex calcified coronary lesions: the randomized ROTAXUS (Rotational Atherectomy Prior to Taxus Stent Treatment for Complex Native Coronary Artery Disease) trial. JACC Cardiovasc Interv. 2013;6(1):10-9.

11. De Waha S, Allali A, Büttner H-JJ, Toelg R, Geist V, Neumann F-JJ, Khattab AA, Richardt G, Abdel-Wahab M. Rotational atherectomy before paclitaxel-eluting stent implantation in complex calcified coronary lesions: Two-year clinical outcome of the randomized ROTAXUS trial. Catheter Cardiovasc Interv. 2016;87(4):691-700.

12. Stefanini GG, Holmes DR. Drug-eluting coronary-artery stents. N Engl J Med. 2013;368(3): 254-65.

13. Planer D, Smits PC, Kereiakes DJ, Kedhi E, Fahy M, $\mathrm{Xu} \mathrm{K}$, Serruys PW, Stone GW. Comparison of 
everolimus- and paclitaxel-eluting stents in patients with acute and stable coronary syndromes: pooled results from the SPIRIT (A Clinical Evaluation of the XIENCE V Everolimus Eluting Coronary Stent System) and COMPARE (A Trial of Everolimus-Eluting Stents and Paclitaxel-Eluting Stents for Coronary Revascularization in Daily Practice) Trials. JACC Cardiovasc Interv. 2011;4(10):1104-15.

14. Tian W, Mahmoudi M, Lhermusier T, Pendyala LK, Kiramijyan S, Saar M, Ota H, Chen F, Torguson R, Suddath WO, Satler LF, Pichard AD, Waksman R. Clinical outcomes of first- and second-generation drug-eluting stents in patients undergoing rotational atherectomy for heavily calcified coronary lesions. Cardiovasc Revasc Med. 2015;16(3):147-50.

15. Cutlip DE, Windecker S, Mehran R, Boam A, Cohen DJ, van Es G-AA, Steg PG, Morel MA, Mauri L, Vranckx P, McFadden E, Lansky A, Hamon M, Krucoff MW, Serruys PW. Clinical end points in coronary stent trials: a case for standardized definitions. Circulation. 2007;115(17):2344-51.

16. Vliegenthart R, Oudkerk M, Hofman A, Oei H-HSH, van Dijck W, van Rooij FJ, Witteman JC. Coronary calcification improves cardiovascular risk prediction in the elderly. Circulation. 2005;112(4):572-7.

17. Vavuranakis M, Toutouzas K, Stefanadis C, Chrisohou C, Markou D, Toutouzas P. Stent deployment in calcified lesions: can we overcome calcific restraint with high-pressure balloon inflations? Catheter Cardiovasc Interv. 2001;52(2):164-72.

18. Tan K, Sulke N, Taub N, Sowton E. Clinical and lesion morphologic determinants of coronary angioplasty success and complications: current experience. J Am Coll Cardiol. 1995;25(4):855-65.

19. De Ribamar Costa J, Mintz GS, Carlier SGG, Mehran R, Teirstein P, Sano K, Liu X, Lui J, Na Y, Castellanos C, Biro S, Dani L, Rinker J, Moussa I, Dangas G, Lansky AJ, Kreps EM, Collins M, Stone GW, Moses JW, Leon MB. Nonrandomized comparison of coronary stenting under intravascular ultrasound guidance of direct stenting without predilation versus conventional predilation with a semi-compliant balloon versus predilation with a new scoring balloon. Am J Cardiol. 2007;100(5):812-7.

20. Windecker S, Kolh P, Alfonso F, Collet J-PP, Cremer J, Falk V, Filippatos G, Hamm C, Head SJ, Jüni P, Kappetein AP, Kastrati A, Knuuti J, Landmesser U, Laufer G, Neumann F-JJ, Richter DJ, Schauerte P, Sousa Uva M, Stefanini GG, Taggart DP, Torracca L, Valgimigli M, Wijns W, Witkowski A. 2014 ESC/EACTS Guidelines on myocardial revascularization: The Task Force on Myocardial Revascularization of the European Society of Cardiology (ESC) and the European Association for Cardio-Thoracic Surgery (EACTS)
Developed with the special contribution of the European Association of Percutaneous Cardiovascular Interventions (EAPCI). Eur Heart J. 2014;35(37):2541-619.

21. Madhavan MV, Tarigopula M, Mintz GS, Maehara A, Stone GW, Généreux P. Coronary artery calcification: pathogenesis and prognostic implications. J Am Coll Cardiol. 2014;63(17):1703-14.

22. Généreux P, Madhavan MV, Mintz GS, Maehara A, Palmerini T, Lasalle L, Xu K, McAndrew T, Kirtane A, Lansky AJ, Brener SJ, Mehran R, Stone GW. Ischemic outcomes after coronary intervention of calcified vessels in acute coronary syndromes. Pooled analysis from the HORIZONS-AMI (Harmonizing Outcomes with Revascularization and Stents in Acute Myocardial Infarction) and ACUITY (Acute Catheterization and Urgent Intervention Triage Strategy) TRIALS. J Am Coll Cardiol. 2014;63(18):1845-54.

23. Sarno G, Lagerqvist B, Fröbert O, Nilsson J, Olivecrona G, Omerovic E, Saleh N, Venetzanos D, James $S$. Lower risk of stent thrombosis and restenosis with unrestricted use of "new-generation" drug-eluting stents: a report from the nationwide Swedish Coronary Angiography and Angioplasty Registry (SCAAR). Eur Heart J. 2012;33(5):606-13.

24. Otsuka F, Vorpahl M, Nakano M, Foerst J, Newell JB, Sakakura K, Kutys R, Ladich E, Finn AV, Kolodgie FD, Virmani R. Pathology of second-generation everolimus-eluting stents versus first-generation sirolimus- and paclitaxel-eluting stents in humans. Circulation. 2014;129(2):211-23.

25. Dangas GD, Serruys PW, Kereiakes DJ, Hermiller J, Rizvi A, Newman W, Sudhir K, Smith RS, Cao S, Theodoropoulos K, Cutlip DE, Lansky AJ, Stone GW. Meta-analysis of everolimus-eluting versus paclitaxel-eluting stents in coronary artery disease: final 3-year results of the SPIRIT clinical trials program (Clinical Evaluation of the Xience V Everolimus Eluting Coronary Stent System in the Treatment of Patients With De Novo Native Coronary Artery Lesions). JACC Cardiovasc Interv. 2013;6(9):914-22.

26. Stone GW, Kedhi E, Kereiakes DJ, Parise H, Fahy M, Serruys PW, Smits PC. Differential clinical responses to everolimus-eluting and Paclitaxel-eluting coronary stents in patients with and without diabetes mellitus. Circulation. 2011;124(8):893-900.

27. Iannaccone $\mathrm{M}$, Barbero $\mathrm{U}, \mathrm{D}^{\prime}$ ascenzo $\mathrm{F}$, Latib $\mathrm{A}$, Pennacchi M, Rossi ML, Ugo F, Meliga E, Kawamoto H, Moretti C, Ielasi A, Garbo R, Colombo A, Sardella G, Boccuzzi GG. Rotational atherectomy in very long lesions: Results for the ROTATE registry. Catheter Cardiovasc Interv. 2016;88(6):E164-72. 